\title{
PENGARUH KUALITAS PELAYANAN TERHADAP KEPUASAN NASABAH PADA BANK BRI SYARIAH KC DENPASAR
}

\author{
Ibrahim Adam ${ }^{1}$ \\ I Made Sumartana ${ }^{2}$ \\ ${ }^{1,2} 1$ Fakultas Ekonomi Universitas Ngurah Rai Denpasar, Bali, Indonesia \\ 1e-mail : ibrahim.adam9496@gmail.com
}

\begin{abstract}
ABSTRAK
Tujuan untuk menganalisis pengaruh kualitas pelayanan terhadap kepuasan nasabah di Bank BRI Syariah KC Denpasar. Penelitian ini merupakan penelitian yang berjenis diskriptif, yaitu penelitian yang menggambarkan obyek-obyek yang berhubungan untuk pengambilan keputusan yang bersifat umum, dengan obyek penelitiannya adalah Bank BRI Syariah KC Denpasar. Teknik pengumpulan data yang digunakan adalah dengan menggunakan kuesioner yang dibagikan kepada 98 responden. Sedangkan teknik analisis data yang digunakan adalah analisis regresi linier sederhana yang terdiri dari uji determinasi dan uji t dengan bantuan program SPSS versi 20. Pengumpulan datanya dilakukan dengan menggunakan kuesioner. Hasil analisis regresi sederhana yaitu $\mathrm{Y}=11,400+0,771 \mathrm{X}$. Adapun pengaruh kualitas pelayanan terhadap kepuasan nasabah tinggi, terlihat dari nilai R square sebesar $0,521(52,1 \%)$ dan sisanya 47,9\% disumbangkan faktor lain yang tidak diteliti. Dan nilai $t$-hitung di peroleh sebesar 10,218 sedangkan nilai $t_{\text {tabel }}$ sebesar 1,985 , ini berarti $t_{\text {-hitung }}$ lebih besar dari pada nilai $t_{\text {tabel }}$, hal ini menunjukan bahwa Ho ditolak dan Ha terima. Sehingga hipotesis yang diterima adalah adanya pengaruh antara kualitas pelayanan terhadap kepuasan nasabah pada Bank BRI Syariah KC Denpasar.
\end{abstract}

Kata Kunci: Kualitas Pelayanan, Kepuasan Nasabah

\begin{abstract}
The purpose to analyze the effect of service quality on customer satisfaction in Bank BRI Syariah KC Denpasar. This research is descriptive type research, that is research which describe related objects for general decision making, with research object is Bank BRI Syariah KC Denpasar. Data collection techniques used is to use a questionnaire distributed to 98 respondents. While the data analysis technique used is a simple linear regression analysis consisting of test determination and t test with the help of SPSS program version 20. Data collection is done by using a questionnaire. The result of simple regression analysis is $Y=11,400+0,771 X$. The influence of service quality to high customer satisfaction, seen from the value of $R$ square of $0,521(52.1 \%)$ and the remaining $47.9 \%$ donated other factors that are not researched. And the value of t-count is 10,218 while the t-table value is 1,985, it means t-count is bigger than t-table value, it shows that Ho is rejected and Ha receives. So the hypothesis received is the influence between the quality of service to customer satisfaction at Bank BRI Syariah KC Denpasar.
\end{abstract}

Keywords: Service Quality, Customer Satisfaction 


\section{PENDAHULUAN}

Dewasa ini tuntutan dan kebutuhan masyarakat akan jasa produk perbankan semakin meningkat, seiring meningkatnya pengetahuan atau kemajuan. Agar masyarakat mau menyimpan uangnya di bank, maka pihak perbankan memberikan rangsangan berupa balas jasa yang akan diberikan kepada para nasabah. Rangsangan dapat berupa kemudahan pembukaan rekening tabungan, bunga yang tinggi, hadiah-hadiah/souvenier, gratis biaya transfer antar rekening, jaminan keamanan atas dana yang di simpan nasabah, fasilitas ATM yang tersebar di seluruh Indonesia, nasabah dapat mengambil dan menyetor setiap harinya tanpa di batasi.

Pada situasi persaingan perbankan, bank-bank membutuhkan usaha yang keras untuk mendapat calon nasabah dan mempertahankan yang sudah ada ditangan. Keberhasilan usaha tersebut sangat ditentukan oleh kemampuan perusahaan dalam memberikan pelayanan yang berkualitas. Kualitas pelayanan tercermin dari kepuasan nasabah untuk melakukan penggunaan ulang jasa perbankan. Kepuasan nasabah dalam menggunakan jasa atau produk yang ditawarkan dapat dijadikan masukan bagi pihak manajemen untuk meningkatkan dan memperbaiki kualitas pelayanan yang diberikan. Untuk itu karyawan bagian pelayanan sebaiknya selalu memantau kepuasan yang dirasakan oleh nasabah perbankan untuk mencapai loyalitas dari para nasabah.

Begitu pula dengan bank syariah juga memegang peranan penting dalam rangka ikut serta memajukan perekonomian Negara dan membantu kebutuhan masyarakat yang berkaitan dengan keuangan. Oleh karena itu bank syariah merupakan bank yang beroperasi dengan prinsip syariah, yaitu aturan perjanjian berdasarkan hukum islam antara bank dan pihak lain dalam penyimpanan dana atau pembiayaan kegiatan usaha. Bank Syariah merupakan lembaga keuangan yang usaha pokoknya memberikan jasa dalam lalu lintas pembayaran dan peredaran uang yang beroperasi yang disesuaikan dengan prinsip-prinsip syariah, yang bertujuan menunjang pelaksanaan pembanguanan nasional dalam rangka meningkatkan keadilan, kebersamaan, dan pemerataan kesejahteraan rakyat.

Pada umumnya, kunci utama untuk memenangkan persaingan adalah memberikan kepuasan kepada nasabah. Kepuasan nasabah akan terpenuhi apabila mereka memperoleh apa yang diinginkan, terutama dari segi kualitas pelayanan yang mereka dapatkan. Kepuasan yang dirasakan nasabah terhadap sebuah jasa yang mereka gunakan akan membawa efek positif terhadap kelangsungan bank yang bersangkutan. Nasabah yang puas akan bertahan, dan tidak berpindah menjadi nasabah bank lain. Hal tersebut menjadi bagian dari promosi yang efektif. Kepuasan nasabah memiliki hubungan erat dengan kualitas pelayanan. Persepsi dari nasabah memberikan suatu dorongan tersendiri untuk menjalin ikatan yang kuat dengan pihak bank.

Pelayanan yang baik harus diberikan oleh semua unsur yang terlibat. Semua harus mau dan mampu memberikan pelayanan yang sama. Masing-masing harus saling mendukung sehingga pelayanan yang diberikan dalam rangka memberikan yang terbaik kepada nasabah dapat optimal, mendorong para bankir untuk lebih inovatif, dalam melakukan berbagai perubahan peningkatan pelayanan yang lebih terarah kepada kepuasan nasabah. 
Disisi yang lain para nasabah semakin kritis dengan kualitas pelayanan yang diharapkan dapat diperoleh dari jasa perbankan yang dipergunakanya. Jika terjadi sesuatu yang tidak diinginkan dalam pelayanan yang berakhir dengan kekecewaan, maka nasabah akan melakukan protes dengan kompensasi memindahkan aktivitas bisnisnya ke bank lain, bahkan lebih buruk lagi dengan melakukan protes melalui media massa yang dapat menghancurkan citra bank tersebut.

Pada BRI Syariah KC Denpasar peranan pelayanan sangat penting karena mereka inilah yang akan menjadi ujung tombak dalam memberikan pelayanan yang baik kepada nasabah sehingga nasabah tersebut merasa puas dan terdorong untuk menjadi nasabah yang loyal. Upaya peningkatan kualitas pelayanan oleh Bank BRI Syariah KC Denpasar bersifat inovatif dan berorientasi pada kepuasan Nasabah. Namun masih muncul pertanyaan, apakah hal tersebut telah benar-benar dapat memberikan kepuasan bagi Nasabah Bank BRI Syariah KC Denpasar yang dapat dilihat dari lima dimensi pelayanan yaitu tangibles (bukti langsung), reliability (kehandalan), responsiveness (daya tanggap), assurance (jaminan) dan empathy (empati).

Tabel 1 : Perkembangan Jumlah Nasabah Bank BRI Syariah KC Denpasar Tahun 2013-2015

\begin{tabular}{ccccc}
\hline \hline Tahun & Tabungan & $\begin{array}{c}\text { Jumlah Nasabah } \\
\text { Deposito }\end{array}$ & Giro & Total \\
\hline 2013 & 1.119 & 178 & 13 & 1.310 \\
2014 & 3.212 & 208 & 17 & 3.431 \\
2015 & 5.098 & 267 & 26 & 5.981 \\
\hline
\end{tabular}

Sumber: Bank BRI Syariah KC Denpasar

Berdasarkan tabel 1 terlihat bahwa jumlah nasabah Bank BRI Syariah KC Denpasar dari tahun ke tahun mengalami peningkatan dari 3.431 nasabah pada tahun 2014 menjadi 5.391 nasabah di tahun 2015. Hal ini menunjukkan kepercayaan masyarakat yang semakin tinggi di Bank BRI Syariah KC Denpasar.

Pertumbuhan nasabah yang terus mengalami peningkatan tersebut menjadikan Bank BRI Syariah KC Denpasar terus melakukan pembenahan dimensi-dimensi kualitas pelayanan untuk memberikan pelayanan terbaik dan meningkatkan kepuasan nasabah. Upaya yang di tempuh antara lain adalah dengan pembenahan internal dan kerja sama dengan mitra strategis misalnya, dengan melakukan peningkatan kualitas sumber daya manusia melalui berbagai pendidikan dan pelatihan, perluasan jaringan kantor, serta penataan sarana dan fasilitas fisik kantor.

Berdasarkan hasil observasi sebelumya pada Bank BRI Syariah KC Denpasar ada nasabah yang mengeluh karena banyaknya 
antrian nasabah dan kurangnya rasa perhatiannya dari pihak Bank BRI Syariah KC Denpasar dalam melakukan hubungan komunikasi dengan nasabah. Hal ini memungkinkan adanya penurunan kualitas pelayanan yang diberikan oleh penyedia jasa yaitu Bank BRI Syariah KC Denpasar sehingga berdampak pada penurunan kepuasan nasabah.

Pokok permasalahan penelitian ini berdasarkan uraian latar belakang masalah di atas adalah : apakah ada pengaruh kualitas pelayanan terhadap kepuasan nasabah pada BRI Syariah KC Denpasar?

\section{METODE PENELITIAN}

Penelitian ini akan dilakukan di Bank BRI Syariah KC Denpasar berlokasi di Jalan Mahendradata No.100X Denpasar. Obyek penelitian adalah kualitas pelayanan dan kepuasan nasabah. Kualitas pelayanan terdiri dari bukti langsung, keandalan, daya tanggap, jaminan dan empati. Berdasarkan sumber data, data primer dalam penelitian ini adalah data yang diperoleh langsung dari sumbernya yang diamati untuk pertama kalinya oleh peneliti, misalnya hasil jawaban dari kuisioner, sedangkan data sekunder yaitu data yang bukan diusahakan sendiri pengumpulannya oleh peneliti melainkan sudah dikumpulkan oleh pihak lain, misalnya struktur organisasi dan perkembangan nasabah.

Pada penelitian ini menggunakan teknik analisis Regresi Linier Sederhana bertujuan untuk mengetahui pengaruh kualitas pelayanan terhadap kepuasan nasabah pada Bank BRI Syariah KC Denpasar, Analisis Determinasi Dipergunakan sebagai alat untuk mengetahui besarnya sumbangan atau kontribusi antara variabel bebas terhadap variabel terikat, dan Analisis uji t (t-test) digunakan untuk membuktikan apakah korelasi yang diperoleh antara mengetahui kualitas pelayanan terhadap kepuasan nasabah, apakah memang benar-benar signifikan.

\section{HASIL DAN PEMBAHASAN}

Analisis Regresi Linier Sederhana

Analisis regresi bertujuan untuk mengetahui pengaruh kualitas pelayanan terhadap kepuasan nasabah pada Bank BRI Syariah KC Denpasar (Umar, 2011:117). Berdasarkan perhitungan dengan bantuan program komputer SPSS version 20.0 for windows diperoleh hasil dari perhitungan konstanta (a) dan koefesien regresi linier sederhana (b) pada lampiran adalah sebagai berikut :

$$
\begin{aligned}
& a=11,400 \\
& b=0,771
\end{aligned}
$$

Dari hasil perhitungan tersebut maka diperoleh persamaan regresi linier sederhana.

$$
\begin{aligned}
& Y=a+b X \\
& Y=11,400+0,771 X
\end{aligned}
$$

Dari hasil persamaan diatas mengetahui nilai kualitas pelayanan terhadap kepuasan nasabah hasil dari nilai konstanta (a) $=11,400$ artinya apabila tidak ada perhatian terhadapkualitas pelayanan atau nilainya adalah konstan maka skor kepuasan nasabah sebesar rata-rata 11,400 dan hasil nilai koefisien regresi (b) memiliki nilai positif, artinya bahwa kualitas pelayanan berpengaruh positif terhadap kepuasan nasabah. Persamaan regresi tersebut memiliki arti bahwa apabila nilai kualitas pelayanan naik/bertambah sebesar 1 satuan unit, maka nilai kepuasan nasabah akan naik/bertambah sebesar 0,771 satuan unit. Sebaliknya, apabila nilai kualitas pelayanan turun/berkurang sebesar 1 unit, maka nilai kepuasan nasabah akan 
turun/berkurang sebesar 0,771 satuan unit.

\section{Analisis Determinasi}

Analisis Determinasi dipergunakan sebagai alat untuk mengetahui besarnya sumbangan atau kontribusi antara variabel bebas terhadap variabel terikat. Untuk mencari koefisien determinasi dapat dihitung dengan jalan mengkuadratkan koefisien korelasi dikalikan seratus persen menurut Sugiyono (2004:308).

Adapun rumus tersebut yaitu :

$\mathrm{D}=\mathrm{R}^{2} \times 100 \%$

Karena nilai dari koefesien korelasi (R) adalah 0,722 maka nilai $\mathrm{R}^{2}$ adalah 0,521 maka perhitungan dari koefesien determinasi adalah sebagai berikut :

$$
\begin{aligned}
& \mathrm{D}=\mathrm{R}^{2} \times 100 \% \\
& \mathrm{D}=0,521 \times 100 \% \\
& \mathrm{D}=52,1 \%
\end{aligned}
$$

Koefisien determinasi (D) yang diperoleh dari hasil perhitungan diatas adalah sebesar52,1\%. Hal ini berarti variabel bebas (kualitas pelayanan) memberikan sumbangan terhadapvariabel terikat (kepuasan nasabah) sebesar 52,1\%. Sisanya sebesar $100 \%-52,1 \%=47,9 \%$ disumbangkan oleh faktor lain yang tidak diteliti.

\section{Analisis Uji t (t-test)}

Analisis Uji t (t-test) digunakan untuk membuktikan apakah korelasi yang diperoleh antara mengetahui kualitas pelayanan terhadap kepuasan nasabah, apakah memang benar-benar signifikan. Dapat dihitung dengan menggunakan langkah-langkah analisis. Langkah-langkah analisis menurut sugiyono (2004:315) adalah sebagai berikut:

a. Perumusan Hipotesis

$$
\begin{aligned}
& \text { Ho : } \beta=0 \text {, Artinya variabel } \\
& \text { kualitas pelayanan } \\
& \text { tidak berpengaruh } \\
& \text { secara signifikan }
\end{aligned}
$$

terhadap kepuasan nasabah pada Bank BRI Syariah KC Denpasar.

Ha : $\beta>0$, Artinya ada pengaruh secara signifikan antara variabel kualitas pelayanan terhadap kepuasan nasabah pada Bank BRI Syariah KC Denpasar.

b. Ketentuan Pengujian

Menggunakan derajat kepercayaan $95 \%$ atau tingkat kesalahan 5\% $(\alpha=0,05)$ dan derajat kebebasan: n-k , uji satu sisi pada sisi kanan diperoleh nilai $\mathrm{t}(\alpha ; \mathrm{n}-\mathrm{k})$. Dimana $\mathrm{n}-\mathrm{k}=98$ $-2=96$. Sehingga besarnya $\mathrm{t}-$ tabel $=\mathrm{t}_{(0,05,96)}=1,98498$.

c. Kriteria Pengujian Adapun kriteria penerimaan atau penolakan hipotesis yang diajukan diatas adalah sebagai berikut :

Ho diterima apabila $t_{\text {-hitung }} \geq \mathrm{t}$. tabel

Ho ditolak apabila $t_{\text {-hitung }}<\mathrm{t}_{\text {-tabel }}$

d. Penentuan t-hitung

Berdasarkan hasil perhitungan SPSS version 20.0 for windows dengan kriteria derajad kebebasan pada lampiran 5 adalah 96, besarnya t-hitung untuk Kualitas Pelayanan X adalah 10,218.

e. Penarikan Kesimpulan

Dari pengujian diatas dapat disimpulkan bahwa t-hitung > ttabel yaitu 10,218>1,98498.

Untuk lebih jelasnya akan di tampilkan kurva dibawah ini.

Gambar 1 Kurva Normal Penerimaan dan Penolakan 
Hipotesis dengan Uji-t Pengaruh Kualitas Pelayanan (X) terhadap Kepuasan

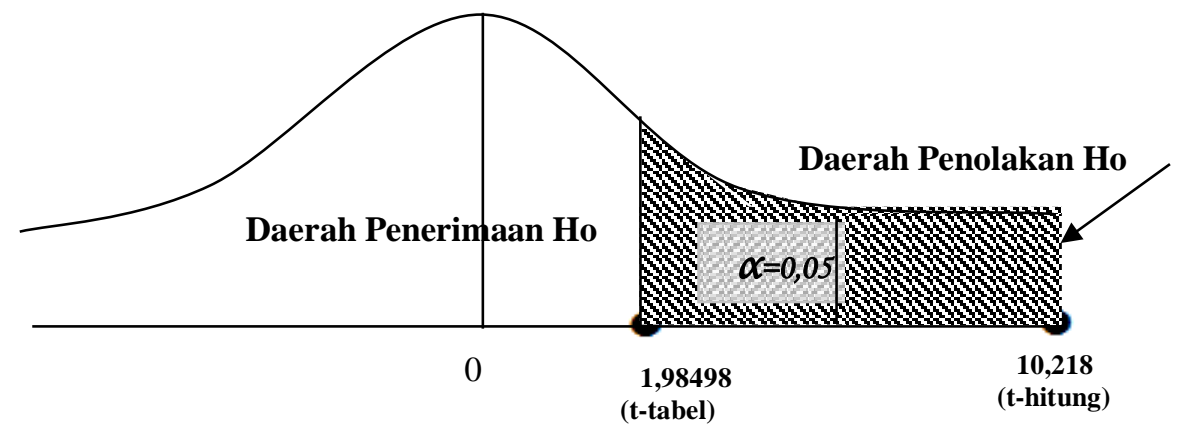

Berdasarkan gambar 1, Dapat diketahui bahwa $\mathrm{t}$-hitung di peroleh sebesar 10,218 sedangkan nilai ttabelsebesar 1,98498, ini berarti t-hitung lebih besar dari pada nilai $t_{- \text {tabel }}$, hal ini menunjukan bahwa Ho ditolak (tidak ada pengaruh kualitas pelayanan terhadap kepuasan nasabah) Ha terima (ada pengaruh kualitas pelayanan terhadap kepuasan nasabah). Sehingga hipotesis yang diterima adalah adanya pengaruh antara kualitas pelayanan terhadap kepuasan nasabah pada Bank BRI Syariah KC Denpasar.

\section{Simpulan}

Dari hasil penelitian yang dibahas dalam bab $\mathrm{v}$ mengenai "Pengaruh Kualitas Pelayanan Terhadap Kepuasan Nasabah Pada Bank BRI Syariah KC Denpasar", dapat disimpulkan sebagai berikut:

1. Ada pengaruh antara kualitas pelayanan terhadap kepuasan nasabah. Hal ini bisa dilihat dari besarnya koefesien regresi 0,771 . Hasil dari uji t, diketahui nilai t-hitung sebesar 10,218 sedangkan nilai t-tabel sebesar 1,98498. Hal ini menunjukkan bahwa Ho ditolak dan $\mathrm{Ha}$ diterima. Maka hasil penelitian membuktikan bahwa kualitas pelayanan mempunyai pengaruh yang positif dan siginifikan terhadap kepuasan nasabah pada Bank BRI Syariah KC Denpasar.

2. Dari koefisien determinasi, diperoleh nilai $\mathrm{R}$ square yaitu 0,521 , artinya besarnya kontribusi variabel kualitas pelayanan terhadap variabel kepuasan nasabah adalah $52,1 \%$, dan sisanya sebesar $47,9 \%$ disumbangkan oleh faktor lain yang tidak diteliti.

\section{Saran}

Berdasarkan kesimpulan yang diperoleh dalam penelitian ini, maka diajukan saran-saran sebagai pelengkap yang dapat diberikan sebagai berikut:

1. Secara keseluruhan pelayanan BRI Syariah KC Denpasar sudah bagus karena dilihat dari tanggapan responden, mayoritas responden menyatakan setuju dengan kualitas pelayanan yang diberikan oleh BRI Syariah KC Denpasar, namun terdapat item pertanyaan yang mayoritas 
menyatakan kurang baik pada bagian Tangible (Bukti Langsung), oleh karena itu bank BRI Syariah KC Denpasar harus meningkatkan Tangible (Bukti Langsung) agar nasabah merasa puas dengan pelayanan yang diberikan.

2. Selain meningkatkan kualitas pelayanan, BRI Syariah KC Denpasar juga harus meningkat kualitas pelayanan yang lain, seperti tempat parkir yang aman, pakaian karyawan yang rapi, ruang tunggu yang nyaman, dan kemudahan nasabah dalam mendapatkan informasi.

\section{REFERENSI}

Ali Mustagfirin, 2015, "Pengaruh Kualitas Pelayanan Terhadap Kepuasan Nasabah di BRI Syariah KCP Demak"

Antonio, Muhamad Syafi'i. 2000. Bank Syariah : Suatu Pengenalan Umum. Cet. 1. Jakarta: Tazkia Institute.

Arifin, Zainul. 2000. Memahami Bank Syariah : Lingkup, Peluang, Tantangan, dan Prospek. Cet.2. Jakarta : Alfabet

Arifin, Zainul. 2004. Bank Syariah Versus Bank Konvensional. Jakarta. Republika

http://www.brisyariah.co.id/

Irawan, Hadi 2005. 10 Prinsip Kepuasan Pelanggan. Elexmedia Komputindo, Jakarta.

Kotler, Philip. 2003. Manajemen Pemasaran. Edisi Mellenium. PT. Prenhallindo. Jakarta.
Kotler, Philip dan Gary Amstrong. 2008. Prinsip-Prinsip Pemasaran Jilid 1. Jakarta : Erlangga.

Kotler, Philip dan Kevin Keller. 2009. Manajemen Pemasaran Jilid 1. Jakarta : Erlangga. 2009. Manajemen Pemasaran Jilid 2. Jakarta : Erlangga.

Lulu Devi Rahmawati, 2014, "Pengaruh Kualitas PelayananTerhadap Kepuasan Nasabah BRI Syariah KCP Sleman Yogyakarta"

Lupiyoadi, Rambat dan Hamdani, A. 2001. Manajemen Pemasaran Jasa. Salemba Empat. Jakarta.

Nasrul, 2014, "Pengaruh Kualitas Pelayanan Terhadap Kepuasan Nasabah Tabungan Pada PT. BPR Pembangunan Nagari Kantor Pusat Lubuk Basung

Sugiyono, 2008. Statistik Untuk Penelitian. Penerbit CV. Alfabeta, Bandung.

Supranto. 2011. Pengkuran Tingakat Kepuasaan Pelanggan untuk Menaikkan Pangsa Pasar. Jakarta: PT Rineka Cipta. Cet. Ke 3.

Tjiptono, Fandy. 2008. Manajemen Jasa. Yogyakarta : Andi Offset.

Umar, Husein. 2011. Desain Penelitian MSDM dan Prilaku Karyawan. Jakarta : PT Raja Grafindo Persada. Cet. Ke 3.

Undang-undang Nomor 21 Tahun 2008 tentang Perbankan Syariah.

Undang-undang Nomor 10 Tahun 1998 tentang Perbedaan Bank Syariah dan Bank Konvensional

Usman, Husain dan Akbar, Purnomo. 2011. Pengantar Statistika. Jakarta: PT Bumi Aksara. 